\title{
Who cares for the older adolescent?
}

\author{
E. L. WATts, Senior Registrar, Child \& Family Psychiatric Unit, St James University \\ Hospital, Leeds; M. E. JenkIns, Consultant Psychiatrist, Brompton House, \\ Northallerton, North Yorkshire; and G. J. R. RICHARDSON, Lime Trees Child, \\ Adolescent \& Family Unit, York
}

One of the first principles on which a good service for adolescents will be based, according to the Health Advisory Service Report Bridges Over Troubled Waters (1986), is "The age group concerned from 12 19 years requires separate consideration and provision". Up to the publication of this report, many adolescent psychiatrists dealt only with those up to the age of 16 (Bruggen \& O'Brien, 1987) or up to school leaving age. Such a recommendation means a considerable change of practice, and this study was designed to assess the nature of that change.

The aims of the study were:

(a) to survey adult psychiatrists' opinions about when people should use adult psychiatric services, rather than adolescent psychiatric services

(b) to survey the work done with adolescents as in-patients and out-patients by adult psychiatrists

(c) to determine the increase in workload such a policy for the 12-19 age range would place on the adolescent psychiatric services.

\section{The study}

The York Adolescent Psychiatric Service provides out-patient and community care to York Health Authority's catchment area. In-patient adolescent psychiatric beds, of which there are 15, are also provided in York, to serve the Health Districts of York, Harrogate, Northallerton and Scarborough. The total catchment population of the four Districts is approximately 615,000 .

All 17 consultant adult psychiatrists in the York, Harrogate and Northallerton and Scarborough Health Districts were asked to complete a questionnaire (available from the authors) seeking their opinions on the management of 12-19 year olds and enquiring about their contact with patients in the 1219 age range. Permission was also obtained from these consultants to collect retrospective data on their inpatients in this age range over the preceding four years and on three of the York consultants' out-patients in this age range over the previous calendar year.

In-patient data from Bootham Park, Clifton \& Naburn Hospitals in York, St Mary's Hospital in
Scarborough and North Yorkshire patients admitted to the Memorial Hospital, Darlington, were examined to determine all those under 20 , who had been admitted to a psychiatric hospital from the four North Yorkshire health districts for the four year period 1983-1986. These figures were compared to the number admitted to the Adolescent Unit, which serves these four health districts, over the same four year period.

The Adolescent Unit in York works in accordance with Bridges over Troubled Waters recommendation 7.1.2 that "Psychiatrists providing services for adolescents have a primary responsibility for all those suffering from identifiable psychiatric disorder", and hence does not exclude patients on grounds of psychosis or life-threatening illness. This practice is at variance with that propounded by Wells (1986) but ensures that all adolescents in North Yorkshire requiring admission are admitted to this Unit.

Out-patient data.were obtained from a random three of the five York consultants who saw adolescents. The number of those under 20 , who had been referred each year was compared with out-patients referred to the adolescent psychiatrist for York health district.

Of the adult psychiatrists, $100 \%$ returned their questionnaires. Adult psychiatrists consider that adulthood begins at an average of 17.75 years, but place faith in their assessment of 'maturity' as an indicator as to which service should serve such patients. Of the $17(75.5 \%)$ consultants, 12 had referrals of those under $20 ; 14(82 \%)$ had treated under 20 year-olds (one had arisen in the family of a referred adult) as out-patients and $12(70.5 \%)$ as in-patients. Only one consultant $(6 \%)$ said he preferred working with the under 20 s, six $(35 \%)$ felt the same about all patients, eight (47\%) liked dealing with this age group less and two (12\%) much less, but only four (23.5\%) wished to give up this age group completely.

Adult psychiatrists were generally content to deal with younger psychotic patients, but wished the adolescent services to deal with teenagers with behavioural, emotional and developmental disorders and anorexia nervosa, especially if family factors were considered of prime importance and the teenager was deemed 'immature'. 
TABLE I

Admissions of those under 20 in North Yorkshire

\begin{tabular}{ccccccccc}
\hline \multicolumn{7}{c}{ Admission to adults' units } & \\
\cline { 1 - 5 } & Age & & & & & \\
Ynder & Age & Age & Age & Age & & Admission to \\
Year & 16 & 16 & 17 & 18 & 19 & Total & adolescent unit \\
\hline 1983 & & 4 & 14 & 20 & 22 & 60 & 28 \\
1984 & 1 & 2 & 5 & 11 & 20 & 39 & 31 \\
1985 & & 2 & 7 & 17 & 18 & 44 & 34 \\
1986 & & 3 & 11 & 9 & 23 & 46 & 18 \\
\hline
\end{tabular}

\section{In-patients}

The details of those under 20 , who were admitted to adult psychiatric facilities from the four North Yorkshire health districts, are given in Table I. The adolescent psychiatric unit, therefore, provides just over a third of the in-patient beds required for those 20.

\section{Out-patients}

From the 1986 out-patient figures of three of the five consultants in York Health District who saw outpatients under 20 , it was clear that they saw at least one new adolescent patient a month, which makes an estimated total of 60 patients per year, compared with 97 new referrals seen by the adolescent psychiatrist in 1986.

\section{Comment}

The adult psychiatrists are confident about dealing with young people under the age of 20 years with definite psychotic disorders; however, the majority find the troubled and troubling youngsters without definite psychiatric disorder, who comprise the majority of adolescent referrals, problematic patients, with whom they would rather not deal.

If adolescent psychiatry is to span the age group 12-20 years, there clearly could be problems mixing such a developmentally disparate age range; for example, a 12 year-old anorexic patient and a 19 year-old amphetamine abuser, in the same in-patient facility, would require a substantially different milieu and management strategy. Indeed, a substantial proportion of those aged between 16 and 19 years seen by the adult psychiatrists were substance abusers and, if taken under the umbrella of adolescent psychiatry, would considerably alter the milieu and methods of operating adolescent in-patient units. At present, adolescent psychiatrists work closely with education and social service departments whose statutory responsibilities became less important when a young person reaches school leaving age.
These support services are not available to the older age range, and if the adolescent psychiatrist is to deal with this older age group, he or she will need to become familiar with the post-school social environmental context, although it is perhaps the very lack of support services for this age range that leads to their falling back onto adult psychiatric services.

If all patients under 20 years were dealt with by adolescent psychiatrists, resources would need to be redirected from adult psychiatry to provide for a threefold increase in in-patient numbers and almost doubling of out-patient numbers. It may even be considered that this age range requires a separate subspeciality. If adolescent psychiatrists were to take on those young people that adult psychiatrists do not consider to have reached adulthood, i.e. the under 18 year-olds, then the number of young people at present admitted to in-patient facilities would only increase by $50 \%$.

To operate the Health Advisory Service recommendation from Bridges Over Troubled Waters, that the age group from 12-19 requires separate consideration and provision, would mean that the provision of adolescent psychiatric care would alter dramatically with a considerable expansion of inpatient facilities. A less dramatic change would occur if adolescent psychiatrists took on all patients under 18 , as this is the age at which their adult psychiatric colleagues consider they have reached maturity.

\section{Acknowledgements}

Our thanks to our most co-operative adult colleagues.

\section{References}

Bruggen, P. \& O'Brien, C. (1987) Helping Families: Systems, Residential and Agency Responsibility. London: Faber \& Faber.

Health Advisory Service (1986) Bridges Over Troubled Waters. London: HMSO.

WeLLS, P. (1986) Cut price adolescent units that meet all needs and none. Bulletin of the Royal College of Psychiatrists, 10, 231-232. 